\title{
Development of the Healthy Purchase Index (HPI): a scoring system to assess the nutritional quality of household food purchases
}

\author{
Marion Tharrey ${ }^{1, *}$, Christophe Dubois ${ }^{2}$, Matthieu Maillot ${ }^{3}$, Florent Vieux $^{3}$, \\ Caroline Méjean ${ }^{1}$, Marlène Perignon ${ }^{1}$ and Nicole Darmon ${ }^{1}$ \\ 'MOISA, INRA, CIHEAM-IAMM, CIRAD, Montpellier SupAgro, Univ Montpellier, Campus Inra-SupAgro de la \\ Gaillarde, 2 place Pierre Viala - Bât. 26, 34060 Montpellier Cedex 2, France: ${ }^{2}$ Aix-Marseille Univ, INSERM, \\ INRA 1260, NORT, Marseille, France: ${ }^{3}$ MS-Nutrition, Marseille, France
}

Submitted 25 January 2018: Final revision received 5 September 2018: Accepted 15 October 2018: First published online 26 November 2018

\begin{abstract}
Objective: To develop an index to assess the nutritional quality of household food purchases based on food expenditures only.

Design: A database of monthly food purchases of a convenience sample of lowincome households was used to develop the Healthy Purchase Index (HPI). The HPI is the sum of two sub-scores based on expenditure shares of food categories in total household food expenditure: the purchase diversity sub-score and the purchase quality sub-score. The first was adapted from an existing diversity score. The second integrated those food categories identified as the best predictors of the nutritional quality of purchases based on associations between expenditure shares of food categories and two nutritional quality indicators: the mean adequacy ratio (MAR) and the mean excess ratio (MER). Correlation between the HPI and a score

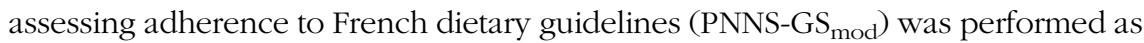
a first validation.

Setting/Particpants: Food purchases of 112 households from deprived neighbourhoods of Marseille (France), participating in the Opticourses and Jassur projects (2012-2015).

Results: The purchase diversity sub-score reflects the presence in food purchases of five food categories: fruits, vegetables, starches, dairy products, and meat, fish \& eggs. The purchase quality sub-score is based on expenditure shares for fruit \& vegetables, added fats \& seasonings, sweet snacks, cheese, sugary drinks, refined grains and fish, as these were identified as predictors of the nutritional quality of purchases. The HPI was positively associated with the PNNS-GS $S_{\text {mod }}\left(r_{\mathrm{s}}=0.378\right.$; $P<0.001)$.

Conclusions: The HPI helps assess the healthiness of household food purchases.
\end{abstract}

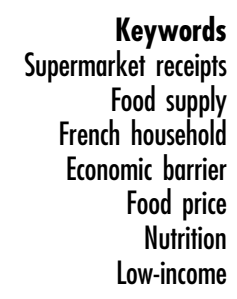

Studies have shown a positive association between diet quality and socio-economic status ${ }^{(1)}$, mediated in part by diet $\operatorname{cost}^{(2)}$. Low-cost diets tend to have high energy density and low nutrient adequacy given that energydense foods are cheaper per kilojoule than recommended nutrient-dense foods ${ }^{(3)}$. Socially disadvantaged people thus run up against more economic barriers hindering the adoption of a healthier diet ${ }^{(4)}$. However, previous research has found that a healthier diet is not necessarily more expensive when households select foods with good nutritional quality for their price ${ }^{(5)}$, making it important to develop decision-support tools to help consumers achieve nutritionally optimal choices at affordable cost.
Despite recent shifts in eating patterns favouring eating out, dietary energy intake in Europe mostly comes from foods consumed at home ${ }^{(6)}$, especially in France ${ }^{(7)}$. Food consumption is therefore driven mainly by household food purchases. Consumer purchasing behaviours have been investigated in both interventional and observational studies, based on analyses of sales data or till receipts. Studies exploring the impact on sales of in-store interventions targeting point-of-purchase food product availability, access, incentives or information have found that modification of the retail store environment can drive consumers towards healthier food purchasing behaviour $^{(8-10)}$. Household till receipts provide unique 
in-depth information on food sources and food items as well as accurate information on expenditures and quantities purchased $^{(11,12)}$. Till receipts have been used in observational studies to characterize household food consumption patterns, especially in relation to different socio-economic characteristics $^{(11,13-15)}$, as they can provide a good estimate of dietary quality and nutrient intakes ${ }^{(12,16,17)}$. Collecting supermarket and grocery receipts was found to provide relevant information on energy and fat intakes ${ }^{(12)}$. Moreover, in households with obese individuals, food purchase provided more reliable information than dietary recalls based on self-reported measures, which are subject to desirability bias and memory failure ${ }^{(16)}$.

However, nutritional analysis of food purchases can prove tedious and time-consuming, typically restricting studies to a few hundred households ${ }^{(5,11-18)}$. Participants are asked to collect and annotate receipts from all family members, and to record all food expenditures made without receipts. Estimating the nutrient content of food expenditures entails cumbersome data handling, especially since evaluators often have to contend with missing data on the quantities purchased ${ }^{(14,19)}$. The present study exploited the huge potential of supermarket receipts for monitoring the nutritional quality of household food purchases to develop a simplified measure of the quality of household food purchases, called the 'Healthy Purchase Index' (HPI). Here we present the methodology used to develop the HPI and the first elements of its validation.

\section{Methods}

\section{Study design and population}

Sociodemographic and food purchase data were obtained from studies conducted on disadvantaged populations in socio-economically deprived neighbourhoods of Marseille (south of France): the Opticourses (2012-2014) and the Jassur (2013-2015) projects. Opticourses participants were ninety-one adults willing to participate in an education programme on food and budget ${ }^{(5,20)}$. Jassur participants were twenty-one adults from the same neighbourhoods with access to a community garden plot $^{(21)}$. All participants ( $n$ 112) completed a monthly record of their household food purchases. All participants provided written informed consent. The Southern Mediterranean Ethical Research Committee Sud-Méditerranée reviewed and approved the protocols of the Opticourses and Jassur trials (registered at clinicaltrials.gov as NCT02383875 and NCT03175575, respectively).

\section{Categorization, price and nutritional composition of bousebold food purchases}

In both studies, participants were asked to provide a detailed record of foods entering their household over a 1-month period (including purchases, gifts and foods from other sources). As previously described in Marty et al. ${ }^{(5)}$, participants were given a notebook with step-by-step instructions on how to collect and annotate all receipts for foods entering the household and to record expenditures without receipts. A face-to-face visit was scheduled approximately $15 \mathrm{~d}$ after the food supply diary was issued to maintain participants' motivation and to ensure correct filling of the diary. A database of monthly food purchases was created by compiling information on date of purchase, quantity and price of all food items purchased. All food items were then classified into nine groups and twenty-three subgroups (Table 1). The 'mixed dishes', 'sweet products' and 'sweet beverages' food groups consist primarily of ultra-processed foods (following the NOVA classification) found to be associated with poor dietary quality and obesity ${ }^{(22,23)}$. For other processed items, such as canned or bottled vegetables, fruits and vegetables or canned fish, various studies have shown no evidence of any extra nutritional benefit of fresh items compared with frozen and canned ones ${ }^{(24-26)}$. In this regard, fresh and processed items were pooled in the same group, as is the case in most indices of overall diet quality.

For each food item purchased, the quantity 'as purchased' was transformed into a quantity 'as consumed' using a correction coefficient that accounted for the changes in weight associated with preparation and waste (e.g. peeling, boning, water loss or gain during cooking, etc.). The nutritional composition of each food item 'as consumed' was then determined by linkage with the closest food from the French food composition table ${ }^{(27)}$. For each household, energy and nutrient contents of food supplies were calculated as the sum of the energy and nutrient contents of all foods and beverages entering the household during the period of data collection.

As previously described ${ }^{(5)}$, missing receipt information on the weight of a food purchased was estimated using three different methods: (i) information on known packaging sizes (and corresponding weights) for that food was searched for on commercial websites and the most plausible weight (given the actual expenditure incurred) was chosen; (ii) when information on packaging sizes was unavailable but the food item was purchased at least twice (with the receipt showing the weights) among all households, we calculated an observed mean food price per kilogram and we then estimated the quantity purchased by dividing the actual expenditure by the corresponding observed mean price; (iii) if we did not have an observed mean food price and the food item was purchased only once in the sample, the quantity purchased was estimated by dividing the actual expenditure by the corresponding national food price. When the food was gifted, picked from the garden or came from food aid, we assigned a theoretical price using the mean observed food price. 
Table 1 Food group and subgroup categorizations of food items purchased by 112 socially disadvantaged households of Marseille (France) participating in the Opticourses and Jassur projects (2012-2015)

\begin{tabular}{lll}
\hline Food group & Food subgroup & Examples of food items included \\
\hline Fruit \& vegetables & Fruits & Fresh fruit, canned fruit, stewed fruit \\
& Dried fruits & Unsalted dried fruit, nuts, seeds \\
& Vegetables & Fresh vegetables, vegetable soup, canned vegetables \\
Starches & Refined grains & Bread rolls, fresh bread, pasta, rice, flour \\
& Unrefined starches & Potatoes, legumes, wholegrain products \\
Dairy products & Cheese & Hard cheese, soft cheese, cream cheese \\
& Milk \& yoghurt & Refrigerated and long-life milk, plain yoghurt, sweetened yoghurt, fruit yoghurt, \\
& & yoghurt drink \\
Meat, fish \& eggs & Eggs \& poultry & Hard-boiled egg, fried egg, omelette, chicken, duck, turkey \\
& Red \& processed meat & Beef, pork, lamb, sausages, bacon, offal \\
& Fish & Fresh fish, canned fish, shellfish, surimi \\
Mixed dishes & Ready meals & Frozen ready meals, canned meals, salads \\
& Savoury snacks & Crackers, chips, salted and roasted nuts, olives \\
Sweet products & Other snacks & Sandwiches, burgers, quiche, pizza \\
& Sweet snacks & Cakes, biscuits, pastries, candies, chocolate \\
Added fats \& seasonings & Breakfast cereals & Breakfast cereals \\
& Dairy desserts & Cream dessert, ice cream \\
& Vegetable fats & Cream, butter \\
Sweet beverages & Sauces & Vegetable oil, margarine, salad dressing \\
& Sugary drinks & Ketchup, sauces including soya/tomato/barbecue, etc. \\
& Fruit juices & Soda, nectars \\
Condiments & Diet soft drinks & Fresh fruit juice, concentrated fruit juice \\
& Spices & Diet soft drinks \\
\hline
\end{tabular}

\section{Indicators of nutritional quality of housebold food purchases}

Mean adequacy ratio (MAR) and mean excess ratio (MER) were used as indicators of the nutritional quality of food purchases and were calculated for $8368 \mathrm{~kJ}$ (2000 kcal) of purchases for each household.

MAR is an indicator of overall good nutritional quality ${ }^{(28)}$. It was calculated as the mean of twenty-three nutrient adequacy ratios, corresponding to percentage of the daily recommended intakes for twenty-three key nutrients as previously described ${ }^{(29)}$ :

$$
\begin{aligned}
\operatorname{MAR}(\% / 8368 \mathrm{~kJ}(2000 \mathrm{kcal}))= & \frac{1}{23} \times \sum_{n=1}^{23}\left(N u t_{n} / R D A_{n}\right) \\
& \times 100
\end{aligned}
$$

where $N u t_{n}$ is the quantity of each nutrient $n$ per $8368 \mathrm{~kJ}$ $(2000 \mathrm{kcal})$ of purchase and $R D A_{n}$ is the French $\mathrm{RDA}^{(30)}$ for that nutrient. As is customary, each nutrient adequacy ratio $\left(N u t_{n} / R D A_{n}\right)$ was truncated at 1 , so that a high intake of one nutrient could not compensate for a low intake of another ${ }^{(31)}$.

Conversely, MER is an indicator of bad nutritional quality. As previously proposed by Vieux et al. ${ }^{(32)}$, MER is the mean of three nutrient excess ratios, corresponding to percentage of the daily maximum recommended value for three unhealthy nutrients: Na, SFA and free sugars (added sugars plus sugars naturally present in honey, syrups and fruit juices), as follows:

$$
\begin{aligned}
\operatorname{MER}(\% / 8368 \mathrm{~kJ}(2000 \mathrm{kcal}))= & \frac{1}{3} \times \sum_{p=1}^{3}\left(N u t_{p} / M R V_{p}\right) \\
& \times 100
\end{aligned}
$$

where $N u t_{p}$ is the quantity of each nutrient $p$ per $8368 \mathrm{~kJ}$ ( $2000 \mathrm{kcal})$ of purchase and $M R V_{p}$ is the maximum recommended value for that nutrient. Here, unlike the previously published $\mathrm{MER}^{(32)}$, each nutrient excess ratio lower than 100 was not truncated to 100 in order to avoid non-normal distribution of the indicator.

\section{Development of the Healthy Purchase Index}

Food expenditure shares corresponding to the percentage expenditure on each food group and subgroup in monthly food expenditure were calculated for each household. Two sub-scores were defined, the purchase diversity subscore and the purchase quality sub-score, and the HPI was calculated as the sum of the two sub-scores.

\section{Purchase diversity sub-score}

The purchase diversity sub-score is a five-component score derived from a previously published individual 'Dietary Diversity Score' that reflects the presence in the diet of five food groups and subgroups: fruits, vegetables, starches, dairy products, and meat, fish \& eggs ${ }^{(33)}$. We considered that an expenditure share of $5 \%$ of total food expenditure would likely correspond to the share accounting for a non-negligible but easily achievable contribution of a food group or subgroup to household food purchases. Therefore, for each of the five food groups and subgroups, 1 point was given when its 
expenditure share was greater than $5 \%$, leading to a maximum value of 5 points for the purchase diversity subscore.

\section{Purchase quality sub-score}

The purchase quality sub-score is a seven-component score. It was based on food groups and subgroups identified according to known relationships between diet and health $^{(34)}$ and/or for which expenditure shares best reflected the nutritional quality of purchases. Identification of best predictors was performed separately for food groups and subgroups. In a first step, regressions were conducted to capture the relationship between each indicator of nutritional quality (i.e. MAR and MER), as the dependent variable, and each food group and subgroup. We then performed multivariate linear regressions for MAR and MER separately, including all main terms yielding $P<0.20$ in the first step. A change-in-estimate method was further applied to select the best subset of predictors. The MAR, MER and food group and subgroup expenditure shares were log-transformed to improve normality. Log transformation of food subgroups rarely purchased (i.e. by less than a third of households) did not reduce skewness and so they were coded as binary variables (purchased/ not purchased). These binary variables were subsequently added to the multivariate models, and only the variables proved significant were kept in the final model. In addition to the identified predictors, several refinements were incorporated based on expert advice from the 2016 report of the French Agency for Food, Environmental and Occupational Health \& Safety (Anses) on the update of the French dietary guidelines ${ }^{(34)}$.

For each predictor significantly associated with one of the nutritional quality indicators, minimum or maximum expenditure shares were defined by identifying breaks in plots crossing predictor expenditure share and nutritional quality indicator. For predictors associated with both MAR and MER, the plot that better reflected breaks in the distribution was chosen to define the cut-off values.

\section{First elements of validation of the Healthy Purchase Index}

A common method for validating a dietary quality index consists in comparing the new index against a previously validated one ${ }^{(35)}$. Here, we used Spearman nonparametric correlations to compare the HPI with the MAR and with the MER (expressed as adequacy and excess ratios, respectively, per $8368 \mathrm{~kJ}$ ( $2000 \mathrm{kcal})$ of purchases), as well as with each of their constitutive nutrient ratios individually. The association with a modified version of the PNNS-Guideline Score (PNNS-GS), assessing adherence to official French dietary guidelines, was also investigated. Briefly, the PNNS-GS is a 15-point score comprising thirteen components: eight components capture French dietary guidelines, four components concern nutrients and food groups whose consumption is to be limited, and one component covers adherence to physical activity recommendations ${ }^{(36)}$. Here, a modified PNNS-GS (PNNS-GS $\mathrm{Sod}_{\text {mod }}$ ), excluding both the physical activity and alcohol components (absent from our database), was computed on each household's monthly food purchases. To do so, weight and energy of household food supplies were divided by number of household members and by number of days of data collection, as French dietary guidelines are stated in terms of individual recommended daily servings.

Sensitivity analysis was also performed by testing the addition of two penalties to the HPI. A first penalty was added when the red \& processed meat expenditure share was higher than the 75 th percentile in the study population, given epidemiological evidence linking high consumption of red and processed meat to diseases ${ }^{(37,38)}$. A second penalty was added when food expenditure was below $3.5 € / \mathrm{d}$ per person, as previous research showed that it is almost impossible to obtain a nutritionally adequate diet below this threshold in France ${ }^{(3,39)}$ and so it is unlikely that food purchases below this threshold have good nutritional quality.

All analyses were performed with the statistical software package SAS version 9.4 for Windows, with statistical significance at $P<0 \cdot 05$.

\section{Results}

\section{Characteristics of the bousebolds}

Mean household size was 3.3 persons (range: 1-7) including 1.6 children (range: 0-6); 20.5\% were singleperson households (data not shown). Almost a third (33.1\%) declared severe financial difficulties, $45.5 \%$ were in a precarious financial situation, $16 \cdot 1 \%$ were in a stable financial situation and $5.3 \%$ did not answer the question. During the 1-month food records, each household shopped in an average of five different stores. A total of 849 different food items were purchased for the whole sample.

\section{The purchase diversity sub-score}

Regarding the expenditure share distributions of the five components of the purchase diversity sub-score, $56 \%$ of the population reached the minimum expenditure share of $5 \%$ for fruits, $75 \%$ for vegetables, $93 \%$ for starches, $97 \%$ for meat, fish \& eggs, and $85 \%$ for dairy products.

\section{The purchase quality sub-score}

Identification of food groups and subgroups for which expenditure shares best predict the nutritional quality of purchases

The major contributors to total household food expenditure were meat, fish \& eggs (26.7 (SD 12.8) \%), starches 
(17.4 (SD 11.3) \%), fruit \& vegetables (16.6 (SD 10.0) \%), sweet products $(12 \cdot 4$ (SD $7 \cdot 2) \%$ ) and dairy products $(10 \cdot 3$ (SD 5.3 ) \%) for the food groups; and red \& processed meat (15.0 (SD 10.9) \%), refined grains (14.2 (SD 11.2) \%), sweet snacks (10.9 (SD 6.7) \%) and vegetables (9.5 (SD 6.3) \%) for the subgroups. The expenditure share for condiments was negligible (i.e. less than $1.5 \%$ ) and this subgroup was thus excluded from the analysis. Of the twenty-two subgroups, ten were coded as binary variables. Results from bivariate associations and final multivariate models are presented in Table 2. A total of fourteen predictors - six food groups and eight subgroups - were found to be significantly associated with at least one indicator of the nutritional quality of purchases in the final multivariate models. Expenditure shares for fruit \& vegetables (including the fruits, dried fruits and vegetables subgroups) and meat, fish \& eggs were positively associated with MAR, while the added fats \& seasonings group (especially vegetable fats) was negatively associated with MAR. Expenditure shares for sweet products and sweet beverages (especially sugary drinks), and for the cheese and sweet snacks subgroups, were positively associated with MER. Expenditure shares for starches and for refined grains were negatively associated with both MAR and MER.

\section{Choice of components included in the purchase quality} sub-score

Owing to their nutritional specificity, subgroups were preferentially selected over food groups to be included in the purchase quality sub-score, apart from the fruit \& vegetables group (given that all its subgroups were predictors of the nutritional quality of purchases). Refined grains were not encouraged as they were found to be negatively associated with both MAR and MER. Thus, the purchase quality

Table 2 Bivariate and multivariate associations between indicators of nutritional quality (mean adequacy ratio (MAR) and mean excess ratio (MER)) of $8368 \mathrm{~kJ}(2000 \mathrm{kcal})$ of food purchases (as dependent variables) and food group and subgroup expenditure shares (in percentage; as independent variables) for 112 socially disadvantaged households of Marseille (France) participating in the Opticourses and Jassur projects (2012-2015)

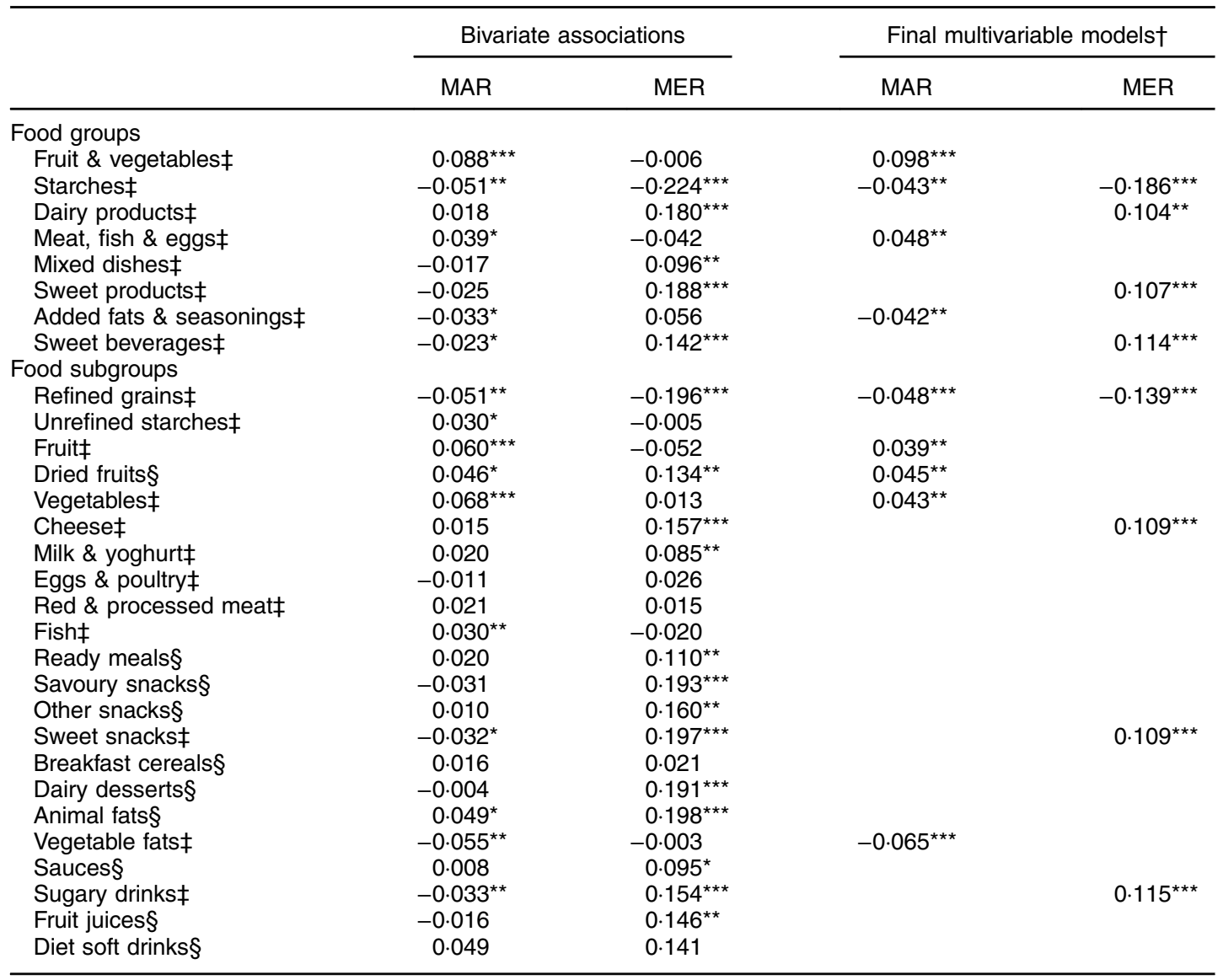

${ }^{\star} P<0.1,{ }^{\star \star} P<0.05,{ }^{\star \star \star} P<0.001$.

†The final multivariate models included all independent variables with $P<0.20$ in the bivariate analyses, followed by change-in-estimate analyses to select the best subset of predictors.

$\ddagger$ Variables were log-transformed. Bivariate associations were assessed by simple linear regressions.

$\S$ Variables were coded as binary variables (purchasers/non-purchasers). Bivariate associations were assessed by analysis of variance models with non-purchasers as reference. 
sub-score was primarily built on five components: fruit \& vegetables (with minimum expected expenditure share), sweet snacks, cheese, sugary drinks (with maximum expected expenditure share), and added fats \& seasonings (with maximum expenditure share and consideration of vegetable fats purchases). Two further components were added in the light of the updated French national dietary guidelines ${ }^{(34)}$ : (i) one limiting the expenditure share of the refined grains subgroup within the starches food group, since cutting back on refined grains and choosing whole grains and higher-quality sources of starches is recommended for health; and (ii) one encouraging expenditure for the fish subgroup, since fish (especially fatty fish) is a unique source of important nutrients such as vitamin D and n-3 fatty acids.

Finally, the purchase quality sub-score is a 10-point score that comprises seven components: two with an expenditure share to increase (fruit \& vegetables, fish) and five with an expenditure share to limit (added fats \& seasonings, sweet snacks, cheese, sugary drinks, refined grains). One or two cut-off values were graphically identified for each component, providing the basis for constructing the sub-score (Table 3).

Table 3 Construction of the Healthy Purchase Index (total out of 15)

\begin{tabular}{|c|c|c|}
\hline Components & Scoring criteria† & Score \\
\hline \multicolumn{3}{|l|}{ Purchase diversity sub-score } \\
\hline Fruit & $\begin{array}{l}{[0-5[} \\
\geq 5\end{array}$ & $\begin{array}{l}0 \\
1\end{array}$ \\
\hline Vegetables & $\begin{array}{l}{[0-5[} \\
\geq 5\end{array}$ & $\begin{array}{l}0 \\
1\end{array}$ \\
\hline Starches & $\begin{array}{l}{[0-5[} \\
\geq 5\end{array}$ & $\begin{array}{l}0 \\
1\end{array}$ \\
\hline Meat, fish \& eggs & $\begin{array}{l}{[0-5[} \\
\geq 5\end{array}$ & $\begin{array}{l}0 \\
1\end{array}$ \\
\hline Dairy products & $\begin{array}{l}{[0-5[} \\
\geq 5\end{array}$ & $\begin{array}{l}0 \\
1\end{array}$ \\
\hline \multicolumn{3}{|l|}{ Purchase quality sub-score } \\
\hline Fruit \& vegetables & $\begin{array}{l}{[0-15[} \\
{[15-25[} \\
\geq 25\end{array}$ & $\begin{array}{l}0 \\
1 \\
2\end{array}$ \\
\hline Added fats \& seasonings & $\begin{array}{c}\geq 3 \\
{[0-3[, \text { and Vegetable fats }=0} \\
{[0-3[, \text { and Vegetable fats }>0}\end{array}$ & $\begin{array}{l}0 \\
0 \\
1\end{array}$ \\
\hline Sweet snacks & $\begin{array}{c}{[0-5[} \\
{[5-10[} \\
\geq 10\end{array}$ & $\begin{array}{l}2 \\
1 \\
0\end{array}$ \\
\hline Cheese & $\begin{array}{l}{[0-5[} \\
>5\end{array}$ & $\begin{array}{l}1 \\
0\end{array}$ \\
\hline Sugary drinks & $\begin{array}{l}{[0-3[} \\
\geq 3\end{array}$ & $\begin{array}{l}1 \\
0\end{array}$ \\
\hline Refined grains & $\begin{array}{l}\geq 1 / 2 \text { Starchesł } \\
<1 / 2 \text { Starches }\end{array}$ & $\begin{array}{l}0 \\
1\end{array}$ \\
\hline Fish & $\begin{array}{l}{[0-5[} \\
{[5-10[} \\
\geq 10\end{array}$ & $\begin{array}{l}0 \\
1 \\
2\end{array}$ \\
\hline
\end{tabular}

†Expressed as a percentage of household monthly food expenditure, unless indicated otherwise.

fExpenditure share of the refined grains subgroup within the starches group.

\section{The Healthy Purchase Index}

The HPI, aimed at evaluating the nutritional quality of monthly household food purchases, is obtained by summing the purchase diversity sub-score and the purchase quality sub-score. Scoring and cut-off values of the HPI are presented in Table 3. The HPI has a maximum of 15 points, where a higher score reflects a higher quality of the household food purchases. The distributions of the HPI score and its sub-scores in the food purchases of the studied population are presented in Fig. 1. Mean HPI score was $7 \cdot 4$ (SD $2 \cdot 1$; range: $3-12$ out of 15 ), with a mean purchase diversity sub-score of $4 \cdot 1$ (SD $0 \cdot 9$; range: $1-5$ out of 5 ) and a mean purchase quality sub-score of $3 \cdot 3$ (SD 1.8; range: $0-8$ out of 10 ; Table 4 ).

The HPI was positively associated with the MAR $\left(r_{\mathrm{s}}=0.552, P<0.001\right)$ and with the PNNS-GS $S_{\text {mod }}\left(r_{\mathrm{s}}=0.378\right.$, $P<0.001)$ and negatively associated with the MER $\left(r_{\mathrm{s}}=-0.426, P<0.001\right)$. Correlations were higher for the purchase quality sub-score than for the purchase diversity sub-score.

Adding a penalty to HPI for households with expenditure shares for red \& processed meat $\geq 20 \%$ ( 75 th percentile) barely attenuated the associations with the three indicators (MAR: $r_{\mathrm{s}}=0.492 ; \quad$ MER: $r_{\mathrm{s}}=-0.396$; PNNS$\mathrm{GS}_{\text {mod }}: r_{\mathrm{s}}=0.334$; all $\left.P<0.001\right)$. Adding a penalty for food budget below $3.5 € / d$ per person (62\% of households) barely changed the associations (MAR: $r_{\mathrm{s}}=0.523$; MER: $r_{\mathrm{s}}=-0.398$; PNNS-GS mod $r_{\mathrm{s}}=0.401$; all $P<0.001$; data not shown).

Associations with nutrient adequacy ratios and nutrient excess ratios of each component of the MAR and MER, respectively, are presented in Table 5. HPI correlated significantly with nineteen nutrients of the MAR $\left(-0.277<r_{\mathrm{s}}<0.557\right)$ and with two nutrients of the MER $\left(-0.478<r_{\mathrm{s}}<-0 \cdot 217\right)$.

\section{Discussion}

Since a healthy diet results in part from healthier choices at the grocery store, the HPI was designed as a tool to evaluate the nutritional quality of household food purchases. Its major strength is that the HPI only needs expenditure shares of specific food groups and subgroups to be calculated. The methodology used to develop the HPI followed a step-by-step process guiding the identification of food groups and subgroups for which expenditure shares best predict the nutritional quality of purchases, the choice of the cut-off values for the identified predictors and the development of the scoring system.

Compared with declarative dietary surveys, food expenditure surveys present the advantage of limiting memory bias and social desirability bias. In particular, when both expenses and quantities are recorded through annotated receipt collection, very detailed data on 
(a)

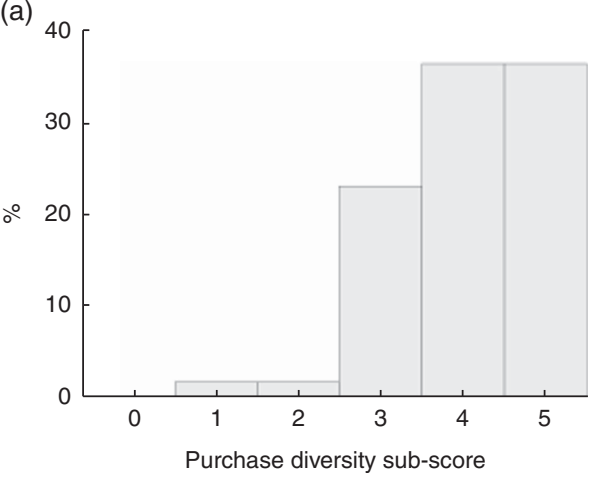

(b)

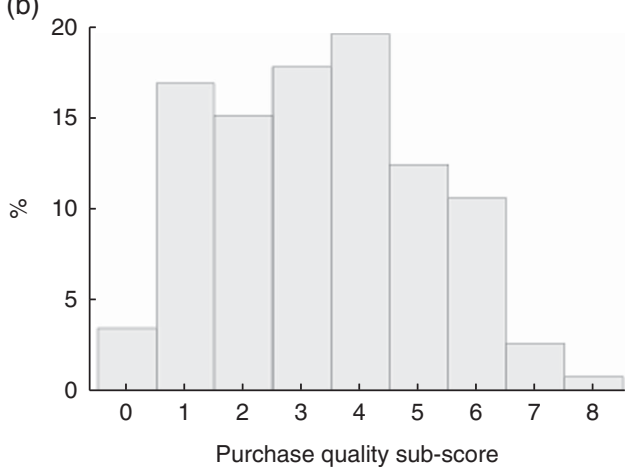

(c)

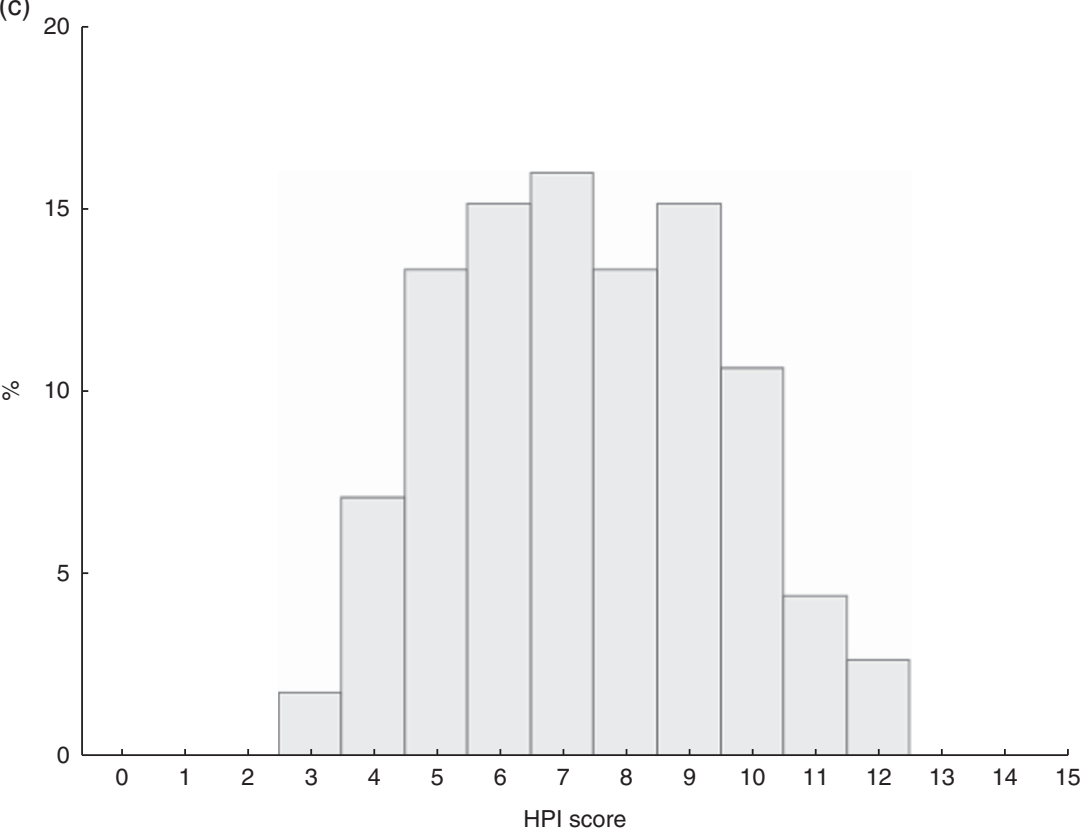

Fig. 1 Distribution of the (a) the purchase diversity sub-score (mean score $=4.1$ (SD 0.9), median score $=4.0$, out of 5 ), (b) the purchase quality sub-score (mean score $=3.3$ (SD 1.8), median score $=3.0$, out of 10) and (c) the final Healthy Purchase Index (HPI) score (mean score $=7.4$ (SD 2.1), median score $=7 \cdot 0$, out of 15) among 112 socially disadvantaged households of Marseille (France) participating in the Opticourses and Jassur projects (2012-2015)

Table 4 Spearman correlations of the Healthy Purchase Index (HPI) and its sub-scores with the mean adequacy ratio

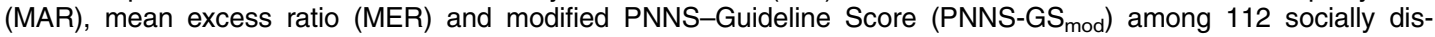
advantaged households of Marseille (France) participating in the Opticourses and Jassur projects (2012-2015)

\begin{tabular}{|c|c|c|c|c|c|}
\hline & \multicolumn{2}{|c|}{ Score } & \multicolumn{3}{|c|}{ Spearman correlations } \\
\hline & Mean & SD & MAR & MER & PNNS-GS ${ }_{\text {mod }}$ \\
\hline HPI & 7.4 & $2 \cdot 1$ & $0.522^{\star \star \star}$ & $-0.426^{\star \star \star}$ & $0.378^{\star \star \star}$ \\
\hline Purchase diversity sub-score & $4 \cdot 1$ & 0.9 & $0.386^{\star \star \star}$ & -0.001 & 0.135 \\
\hline Purchase quality sub-score & $3 \cdot 3$ & $1 \cdot 8$ & $0.419^{* * *}$ & $-0.499^{\star \star *}$ & $0.403^{\star \star \star}$ \\
\hline
\end{tabular}

${ }^{* * *} P<0.001$

household food purchases can be obtained ${ }^{(11)}$. Quantities purchased are more difficult to obtain, but when recorded in addition to expenditure data, they yield reliable information on the cost of food ${ }^{(3)}$. Moreover, when linked to a food composition table, till receipts were found to provide good estimates of the household intakes of energy and percentage energy from fat ${ }^{(12,16)}$. More recently, Appelhans et al. found that household food purchases yielded a reasonable estimate of overall diet quality for primary household food shoppers ${ }^{(17)}$. 
Table 5 Spearman correlations of the Healthy Purchase Index (HPI) and its sub-scores with the adequacy and excess ratios of each nutrient included in the mean adequacy ratio and mean excess ratio, respectively, among 112 socially disadvantaged households of Marseille (France) participating in the Opticourses and Jassur projects (2012-2015)

\begin{tabular}{|c|c|c|c|}
\hline & Purchase diversity sub-score & Purchase quality sub-score & $\mathrm{HPI}$ \\
\hline \multicolumn{4}{|c|}{ Nutrient adequacy ratios $†$} \\
\hline Proteins & 0.0243 & $0.301^{* *}$ & $0.274^{\star \star}$ \\
\hline DHA & $0.161^{\star}$ & $0.263^{\star *}$ & $0.255^{\star \star}$ \\
\hline Vitamin A & $0.429^{\star * \star}$ & $0 \cdot 194^{\star *}$ & $0.360^{\star * *}$ \\
\hline Fibre & $0.378^{\star \star \star}$ & $0.452^{\star \star \star}$ & $0.543^{\star \star \star}$ \\
\hline Linolenic acid & -0.011 & 0.026 & 0.036 \\
\hline Linoleic acid & 0.0014 & $-0.328^{\star \star *}$ & $-0.277^{\star \star}$ \\
\hline Thiamin & $0.192^{\star *}$ & $0.360^{\star \star \star}$ & $0.388^{\star \star \star}$ \\
\hline Riboflavin & $0.283^{\star \star}$ & 0.075 & 0.149 \\
\hline Niacin & -0.010 & $0.231^{\star \star}$ & $0.172^{\star}$ \\
\hline Vitamin $B_{6}$ & 0.123 & $0 \cdot 398^{\star * \star}$ & $0.355^{\star \star *}$ \\
\hline Folates & $0.374^{\star \star \star}$ & $0.411^{\star * \star}$ & $0.519^{* * *}$ \\
\hline Vitamin $B_{12}$ & -0.068 & 0.135 & 0.054 \\
\hline Vitamin C & 0.224 & 0.135 & $0 \cdot 197^{\star}$ \\
\hline Vitamin E & 0.014 & $-0.193^{\star \star}$ & -0.127 \\
\hline Vitamin $\bar{D}$ & 0.110 & $0.231^{\star *}$ & $0.231^{\star \star}$ \\
\hline $\mathrm{Ca}$ & $0.268^{\star \star}$ & 0.027 & 0.127 \\
\hline $\mathrm{K}$ & $0.278^{\star \star}$ & $0.438^{\star \star \star}$ & $0.469^{\star \star *}$ \\
\hline $\mathrm{Mg}$ & $0.307^{\star \star}$ & $0.498^{\star \star \star}$ & $0.557^{\star \star \star}$ \\
\hline lodine & $0.279^{\star \star}$ & $0.373^{\star \star \star}$ & $0.431^{\star \star \star}$ \\
\hline $\mathrm{Se}$ & $0 \cdot 175^{\star}$ & $0.484^{\star * \star}$ & $0.483^{\star \star *}$ \\
\hline $\mathrm{Cu}$ & $0.318^{\star \star \star}$ & $0.414^{\star * \star}$ & $0.480^{\star \star \star}$ \\
\hline $\mathrm{Zn}$ & 0.009 & $0.241^{\star \star}$ & $0.201^{\star *}$ \\
\hline $\mathrm{Fe}$ & 0.152 & $0.263^{\star \star}$ & $0.271^{\star \star}$ \\
\hline \multicolumn{4}{|c|}{ Nutrient excess ratios $\ddagger$} \\
\hline $\mathrm{Na}$ & -0.047 & -0.083 & -0.089 \\
\hline SFA & 0.077 & $-0.308^{\star \star *}$ & $-0.217^{\star \star}$ \\
\hline Free sugars & -0.037 & $-0.526^{\star \star \star}$ & $-0.478^{\star \star \star}$ \\
\hline
\end{tabular}

${ }^{\star} P<0.1,{ }^{* \star} P<0.05,{ }^{* \star *} P<0.001$

†Percentage of the daily recommended intakes for $8368 \mathrm{~kJ}(2000 \mathrm{kcal})$ of purchases.

‡Percentage of daily maximum recommended values for $8368 \mathrm{~kJ}(2000 \mathrm{kcal})$ of purchases.

However, using this information (expenditure on food quantities purchased, energy and nutrient contents) to assess household food purchase patterns and nutritional quality is a tedious and costly task (data entry, coding, linkage with nutrition information, analysis, etc.), and can burden both research staff and participants. Such methodological difficulties in evaluating the quality of household food purchases can be solved by an approach based solely on food expenditure. To the best of our knowledge, only two studies have used food budget shares to assess the nutritional quality of food purchases. In 2012, considering that most food choices are made at the supermarket or grocery store, the US Department of Agriculture proposed several tools to assess the overall healthfulness of food purchases, including scores based on food category expenditure shares ${ }^{(40)}$. These scores compared observed expenditure shares with reference expenditure shares, the latter being derived from mathematically optimized food baskets meeting the RDA for all nutrients ${ }^{(41)}$. However, the cultural acceptability of such theoretical baskets has been questioned ${ }^{(42)}$. In 2015 , the Healthy Trolley Index - in which daily servings of food groups (as a percentage of the total recommended daily serving) were simply translated into the proportion of monthly expenditure per food group - was developed by an Australian research team to compare food expenditure with the Australian Guide to Healthy Eating ${ }^{(43)}$. The HPI, by design, has the advantage of directly accounting for food group and subgroup expenditure shares without needing information on the weight and nutritional composition of the foods. The HPI thus overcomes the fact that proportion by weight does not necessarily align with proportion by price, as some food groups are more expensive than others ${ }^{(44)}$. This food price hierarchy was ignored in the Australian Healthy Trolley Index ${ }^{(43)}$, which did not take into account that fruit, vegetables and meat provide more costly kilojoules than starches and fats ${ }^{(3)}$.

To be consistent with many dietary guidelines that emphasize the importance of increasing both diversity and quality to achieve a healthy balanced $\operatorname{diet}^{(45-47)}$, the HPI included two sub-scores: the purchase diversity sub-score and the purchase quality sub-score. Various indices differing in the number of food categories used have been developed to assess dietary diversity ${ }^{(28,48)}$. For the purchase diversity sub-score we settled on fruit, vegetables, starches, meat, fish \& eggs, and dairy products, as an omission of one or more of these five categories was found to be associated with increased risk of mortality $^{(49,50)}$. The purchase diversity sub-score is therefore a 
five-component score designed to reflect the presence of five food groups (and subgroups) in total household food expenditure. Rather than encouraging diversity, the subscore can be viewed as a way to penalize unbalanced food baskets in which at least one of the five food groups (and subgroups) is lacking. The purchase quality sub-score is aimed at capturing the nutritional quality of household food purchases through expenditure shares of specific groups (and subgroups) and French dietary guidelines. The purchase quality sub-score is a seven-component score: two components with expenditure shares to be increased and five components with expenditure shares to be limited to pursue health objectives. Furthermore, the purchase quality sub-score indirectly encourages intragroup diversity through its design including various food groups and subgroups. The HPI, which sums the two subscores, showed good agreement with MAR and MER, two indicators of diet quality based on nutrients only. This association may have resulted in part from the fact that MAR and MER were closely related to the HPI, as they were used to construct the purchase quality sub-score. However, similar correlations were obtained with an unrelated indicator of diet quality based on foods and food groups (the PNNS-GS $S_{\text {mod }}$ ), thereby providing preliminary evidence of the capacity of the HPI to assess food purchase quality. In addition, the associations of the HPI with MAR, MER and PNNS-GS $S_{\text {mod }}$ were relatively strong, of the same order of magnitude as or greater than values previously found between MAR and other diet quality indicators $^{(51,52)}$. No stronger association was found between HPI and the other index scores when adding penalties for expenditure shares for red \& processed meat $\geq 20 \%$ of food budget and for household food purchases below $3.5 € / d$ per person. However, given the specific economic constraints and cultural habits of the studied population ${ }^{(5)}$, which may impact food purchase patterns, it might be worth considering the use of penalties on a larger population with more diverse purchasing behaviours.

Our study has limitations. First, the degree to which HPI reflects actual household consumption patterns is limited by a number of factors: it is based on data at the household level without knowledge of food allocation between different household members or visitors, information on meals eaten away from home was not collected, and what is purchased is not necessarily eaten (waste, leftovers, etc. ${ }^{(17)}$. For all these reasons, it is clear that the HPI cannot claim to be a tool to assess the quality of diets. Second, the HPI was developed based on data from a convenience sample of a limited number of households. Using relatively small convenience samples is a common limitation of studies estimating the nutritional quality of household food purchases ${ }^{(5,11,12,14-18)}$. This limitation is explained by the technical complexity of exploiting annotated supermarket receipts and records, fully justifying the development of a simplified tool like the HPI. Third, keeping records of foods entering the household over a 1-month period places demands on participants that may increase the risks of errors and omissions. Nevertheless, a shorter time window for record-keeping does not seem relevant when salaries and social benefits are paid monthly (as is the case in France). This might be particularly true in disadvantaged populations, where dietary quality was shown to decline over the $30 \mathrm{~d}$ following the receipt of a household's major source of income ${ }^{(53)}$. Fifth, the HPI was developed based on expenditure shares in deprived households with specific food purchase patterns. Individuals involved in the Opticourses and Jassur studies ${ }^{(5,20)}$, which provided the data, are people living in very poor neighbourhoods and many of them were born abroad, in North Africa in particular. It would be useful to assess the external validity of the HPI based on food purchasing data from a more heterogeneous population. Testing the method in other socio-economic and geographical contexts will help refine the index. In particular, it is important to examine the HPI's ability to capture the influence of sociodemographic and economic determinants on the nutritional quality of food choices. Spending on food is a key indicator of household welfare. Engel's law ${ }^{(54)}$ states that as income drops, the proportion of income spent on food increases, but the absolute amount of money available to buy food decreases. Assessing the validity of the HPI at different income levels is therefore a research priority. Another line of enquiry would be to examine how the index is affected by the variability of food prices.

\section{Conclusion}

The HPI is a score evaluating the nutritional quality of household food purchases based exclusively on food expenses incurred. The HPI offers a simple and effective tool to assess the nutritional quality of household food purchases that may help improve the healthfulness of food purchases.

\section{Acknowledgements}

Acknowledgements: The authors would like to thank Lisa Michel (master's student) for her contribution to the HPI development. Financial support: This work was supported by the French National Cancer Institute (INCA) and the Regional Agency for Health in Provence-Alpes-Cote d'Azur (Opticourses project) and the French National Agency of Research (ANR) (Jassur research project; grant number ANR-12-VBDU-0011). The funding agencies had no role in the design, analysis or writing of this article. Conflict of interest: None. Authorship: N.D., C.D., M.M., F.V. and M.T. designed the research; M.T. and M.M. conducted the research; M.T. analysed the data and wrote the first draft of the manuscript; all the authors interpreted the results, contributed to writing of the manuscript and 
proposed critical comments; N.D. had primary responsibility for final content. All authors read and approved the final manuscript. Ethics of human subject participation: The protocol of the Opticourses and Jassur trails were reviewed by the Comité de Protection des Personnes Sud-Méditerranée which stated that no institutional review board approval was necessary for this research. Written informed consent was obtained from all participants at enrolment and the trials were registered at clinicaltrials.gov as NCT02383875 and NCT03175575, respectively.

\section{References}

1. Darmon N \& Drewnowski A (2008) Does social class predict diet quality? Am J Clin Nutr 87, 1107-1117.

2. Aggarwal A, Monsivais P, Cook AJ et al. (2011) Does diet cost mediate the relation between socioeconomic position and diet quality? Eur J Clin Nutr 65, 1059-1066.

3. Darmon N \& Drewnowski A (2015) Contribution of food prices and diet cost to socioeconomic disparities in diet quality and health: a systematic review and analysis. Nutr Rev 73, 643-660.

4. Beydoun MA \& Wang Y (2008) How do socio-economic status, perceived economic barriers and nutritional benefits affect quality of dietary intake among US adults? Eur J Clin Nutr 62, 303-313.

5. Marty L, Dubois C, Gaubard MS et al. (2015) Higher nutritional quality at no additional cost among low-income households: insights from food purchases of positive deviants. Am J Clin Nutr 102, 190-198.

6. Orfanos P, Naska A, Trichopoulos D et al. (2007) Eating out of home and its correlates in 10 European countries. The European Prospective Investigation into Cancer and Nutrition (EPIC) study. Public Health Nutr 10, 1515-1525.

7. Agence française de sécurité sanitaire des aliments (2009) Étude Individuelle Nationale des Consommations Alimentaires 2 (INCA 2) 2006-2007, Version 2. Paris: Afssa.

8. Seymour J, Yaroch AL, Serdula M et al. (2004) Impact of nutrition environmental interventions on point-of-purchase behavior in adults: a review. Prev Med 39, 108-136.

9. Escaron AL, Meinen AM, Nitzke SA et al. (2013) Supermarket and grocery store-based interventions to promote healthful food choices and eating practices: a systematic review. Prev Chronic Dis 10, E50.

10. Gamburzew A, Darcel N, Gazan R et al. (2016) In-store marketing of inexpensive foods with good nutritional quality in disadvantaged neighborhoods: increased awareness, understanding, and purchasing. Int J Behav Nutr Phys Act 13, 104.

11. French SA, Shimotsu ST, Wall M et al. (2008) Capturing the spectrum of household food and beverage purchasing behavior: a review. J Am Diet Assoc 108, 2051-2058.

12. Ransley JK, Donnelly JK, Khara TN et al. (2001) The use of supermarket till receipts to determine the fat and energy intake in a UK population. Public Health Nutr $\mathbf{4}$, 1279-1286.

13. Rankin JW, Winett RA, Anderson ES et al. (1998) Food purchase patterns at the supermarket and their relationship to family characteristics. J Nutr Educ 30, 81-88.

14. French SA, Wall M, Mitchell NR et al. (2009) Annotated receipts capture household food purchases from a broad range of sources. Int J Behav Nutr Phys Act 6, 37.

15. French SA, Wall M \& Mitchell NR (2010) Household income differences in food sources and food items purchased. Int J Behav Nutr Phys Act 7, 77.
16. Ransley JK, Donnelly JK, Botham H et al. (2003) Use of supermarket receipts to estimate energy and fat content of food purchased by lean and overweight families. Appetite 41, 141-148.

17. Appelhans BM, French SA, Tangney CC et al. (2017) To what extent do food purchases reflect shoppers' diet quality and nutrient intake? Int J Behav Nutr Phys Act 14, 46.

18. Aaron GJ, Keim NL, Drewnowski A et al. (2013) Estimating dietary costs of low-income women in California: a comparison of 2 approaches. Am J Clin Nutr 97, 835-841.

19. Martin SL, Howell T, Duan Y et al. (2006) The feasibility and utility of grocery receipt analyses for dietary assessment. Nutr J 5, 10.

20. Perignon M, Dubois C, Gazan R et al. (2017) Coconstruction and evaluation of a prevention program for improving the nutritional quality of food purchases at no additional cost in a socioeconomically disadvantaged population. Curr Dev Nutr 1, e001107.

21. Martin P, Consalès J-N, Scheromm P et al. (2017) Community gardening in poor neighborhoods in France: a way to re-think food practices? Appetite 116, 589-598.

22. Louzada ML da C, Baraldi LG, Steele EM et al. (2015) Consumption of ultra-processed foods and obesity in Brazilian adolescents and adults. Prev Med 81, 9-15.

23. Louzada ML da C, Ricardo CZ, Steele EM et al. (2018) The share of ultra-processed foods determines the overall nutritional quality of diets in Brazil. Public Health Nutr 21, 94-102.

24. Rickman JC, Barrett DM \& Bruhn CM (2007) Nutritional comparison of fresh, frozen and canned fruits and vegetables. Part 1. Vitamins C and B and phenolic compounds. J Sci Food Agric 87, 930-944.

25. Kapica C (2012) Canned fruits, vegetables, beans and fish provide nutrients at a lower cost compared to fresh, frozen or dried. J Nutr Food Sci $\mathbf{2}, 4$.

26. Miller SR \& Knudson WA (2014) Nutrition and cost comparisons of select canned, frozen, and fresh fruits and vegetables. Am J Lifestyle Med 8, 430-437.

27. The French Information Center on Food Quality (2014) French food composition table Ciqual, Version 2013. https://www.anses.fr/fr/content/table-ciqual-2013 (accessed January 2017).

28. Kant AK (1996) Indexes of overall diet quality. J Am Diet Assoc 96, 785-791.

29. Maillot M, Darmon N, Vieux F et al. (2007) Low energy density and high nutritional quality are each associated with higher diet costs in French adults. Am J Clin Nutr 86, 690-696.

30. Martin A (2001) The 'apports nutritionnels conseillés (ANC)' for the French population. Reprod Nutr Dev 41, 119-128.

31. Madden JP, Goodman SJ \& Guthrie HA. (1976) Validity of the 24-hr recall. Analysis of data obtained from elderly subjects. J Am Diet Assoc 68, 143-147.

32. Vieux F, Soler L-G, Touazi D et al. (2013) High nutritional quality is not associated with low greenhouse gas emissions in self-selected diets of French adults. Am J Clin Nutr 97, 569-583.

33. Kant AK, Block G, Schatzkin A et al. (1991) Dietary diversity in the US population, NHANES II, 1976-1980. J Am Diet Assoc 91, 1526-1531.

34. Agence nationale de sécurité sanitaire de l'alimentation, de l'environnement et du travail (2017) Actualisation des repères du PNNS: révision des repères de consommations alimentaires. Rapport expertise collective, edition scientifique 2016. Maisons-Alfort: Anses.

35. Waijers PMCM, Feskens EJM \& Ocké MC (2007) A critical review of predefined diet quality scores. Br J Nutr 97, 219

36. Estaquio C, Kesse-Guyot E, Deschamps V et al. (2009) Adherence to the French Programme National Nutrition Santé guideline score is associated with better nutrient intake and nutritional status. J Am Diet Assoc 109, 1031-1041. 
37. Battaglia Richi E, Baumer B, Conrad B et al. (2015) Health risks associated with meat consumption: a review of epidemiological studies. Int J Vitam Nutr Res 85, 70-78.

38. Boada LD, Henríquez-Hernández LA \& Luzardo OP (2016) The impact of red and processed meat consumption on cancer and other health outcomes: epidemiological evidences. Food Chem Toxicol 92, 236-244.

39. Darmon N, Ferguson EL \& Briend A (2006) Impact of a cost constraint on nutritionally adequate food choices for French women: an analysis by linear programming. J Nutr Educ Behav 38, 82-90.

40. Volpe R \& Okrent A (2012) Assessing the Healthfulness of Consumers' Grocery Purchases. Economic information Bulletin no. EIB-102. Washington, DC: US Department of Agriculture, Economic Research Service.

41. Carlson A, Lino M \& Fungwe TV (2007) The Low-Cost, Moderate-Cost, and Liberal Food Plans. Alexandria, VA: US Department of Agriculture, Center for Nutrition Policy and Promotion.

42. Wilde PE \& Llobrera J (2009) Using the thrifty food plan to assess the cost of a nutritious diet. J Consum Aff 43, 274-304.

43. Taylor A, Wilson F, Hendrie GA et al. (2015) Feasibility of a Healthy Trolley Index to assess dietary quality of the household food supply. Br J Nutr 114, 2129-2137.

44. Maillot M, Darmon N, Darmon M et al. (2007) Nutrientdense food groups have high energy costs: an econometric approach to nutrient profiling. J Nutr 137, 1815-1820.

45. US Department of Health and Human Services \& US Department of Agriculture (2015) 2015-2020 Dietary Guidelines for Americans, 8th ed. Washington, DC: US Government Printing Office.
46. Public Health England (2017) The Eatwell Guide. Version current February 2017. https://www.gov.uk/government/ publications/the-eatwell-guide (accessed January 2017).

47. French Ministry of Health (2012) The French National Nutrition and Health Program 2011-2015, version December 2012. Paris: Ministry of Health.

48. Kennedy G, Ballard T \& Dop MC (2011) Guidelines for Measuring Household and Individual Dietary Diversity. Rome: FAO.

49. Kant AK, Schatzkin A, Harris TB et al. (1993) Dietary diversity and subsequent mortality in the First National Health and Nutrition Examination Survey Epidemiologic Follow-up Study. Am J Clin Nutr 57, 434-440.

50. Kant AK, Schatzkin A \& Ziegler RG (1995) Dietary diversity and subsequent cause-specific mortality in the NHANES I epidemiologic follow-up study. I Am Coll Nutr 14, 233-238.

51. Dubois L, Girard M \& Bergeron N (2000) The choice of a diet quality indicator to evaluate the nutritional health of populations. Public Health Nutr 3, 357-365.

52. Cheng G, Duan R, Kranz S et al. (2016) Development of a dietary index to assess overall diet quality for Chinese school-aged children: the Chinese Children Dietary Index. J Acad Nutr Diet 116, 608-617.

53. Tarasuk V, McIntyre L \& Li J (2007) Low-income women's dietary intakes are sensitive to the depletion of household resources in one month. J Nutr 137, 1980-1987.

54. Engel E (1895) Die Productions- und Consumtions verhaltnisse des Konigreichs Sachsen. Reprint of the original article of 1857. Bull Int Stat Inst 9, 1-54. 